\title{
THE HEART IN SYSTEMIC LUPUS ERYTHEMATOSUS
}

\author{
BY \\ W. BRIGDEN, E. G. L. BYWATERS, M. H. LESSOF, AND I. P. ROSS \\ From the Cardiac Department, the London Hospital, the Post-Graduate Medical School of London and the \\ Rheumatism Research Unit (M.R.C.), Canadian Red Cross Memorial Hospital, Taplow \\ Received January 23, 1959
}

Systemic lupus erythematosus was originally described by a dermatologist (Kaposi, 1872). The cardiac manifestations of this disease were first noticed by Libman in 1911 and published with Sacks in 1924 (4 cases). Recognition of the full clinical picture and of the interrelationship of the various aspects of the disease was achieved by the Mt. Sinai group in the years 1923-1935 (see Baehr et al., 1935). The first account of the pathology of the cardiac lesions was based on 11 cases (Gross, 1932).

Systemic lupus erythematosus appears to be less common in the British Isles than in the U.S.A., but it has received more attention here in recent years. With wider recognition of the disease the incidence of heart damage has been found to be greater: Humphreys (1948) found cardiac abnormalities in most of 21 cases studied at necropsy, and Harvey et al. (1954) found that 55 per cent of 138 patients had cardiac abnormalities at some stage of their illness, the commonest finding being pericarditis.

Our own observations also show a high incidence of cardiac abnormalities in systemic lupus erythematosus. Heart lesions develop in nearly all patients at some time during the course of their disease when life is prolonged by modern antibiotic and steroid therapy.

\section{Material AND Methods}

Sixty patients have been studied in hospita ${ }^{*}$ in the past ten years. Their ages range from 10 to 54. Only four were female. The diagnosis was based on a combination of features such as polyarthritis, lupus rash, fever, and renal, cardiac, or pulmonary involvement, and a raised sedimentation rate. The incidence of the important systemic manifestations is shown in Table 1. In 50 patients

TABLE I

InCIDENCE of Non-Cardiac Manifestations in 60 Patients WITH SYSTEMIC LUPUS ERYTHEMATOSUS

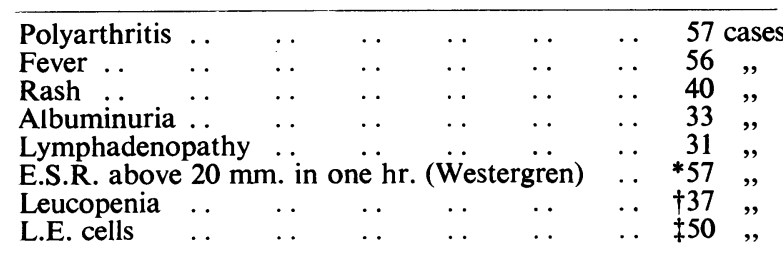

* Not estimated in remaining 3.

+ This leucopenia of $4000 / \mathrm{cu} . \mathrm{mm}$. or below was usually a transient finding in patients who had had several blood counts. Persistent leucopenia was rare.

$\ddagger$ L.E. cells looked for in 55 patients.

* 20 at the Hammersmith Hospital, 28 at the London Hospital, and 12 at the Canadian Red Cross Memorial Hospital, Taplow. 
out of the 55 who were tested, the diagnosis was confirmed by the finding of L.E. cells in peripheral blood. Necropsies were done in 27 of the 31 who died and confirmed the diagnosis. In two patients the diagnosis rested on clinical evidence alone, i.e. L.E. cells have been found and the patients remain alive. All patients had electrocardiograms, most had chest X-rays, and some had phonocardiograms. None have had hæmodynamic studies.

All the patients had the criteria required for diagnosis by the Medical Research Council Collagen Panel (1952-unpublished), except for three with necropsy confirmation of the diagnosis but without confirmation by sedimentation rate. Essential features were a sedimentation rate raised above $20 \mathrm{~mm}$. in 1 hour, and in addition two major features or one major and at least two minor features out of the following lists. Major criteria-(1) rash compatible with disseminated lupus, (2) leucopenia below 5000/cu. mm., (3) the finding of L.E. cells in a 15-minute search. Minor criteria-(1) arthralgia or joint effusions, (2) serositis, (3) fever, (4) retinitis, (5) Rose-Waaler agglutination titre test $1: 16$ or more, (6) albuminuria. It is realized that these criteria may occasionally fit other diseases, and therefore as far as possible other disease was excluded.

\section{PATHOLOGY}

This pathological description is based on 27 necropsy cases. The heart was grossly enlarged (over 400 g.) in 7 out of 21 cases with recorded weights. The Endocardium. The mitral valve was involved frequently (10 out of 27 cases) (Fig. 1-3), the aortic valve four times, the pulmonary valve once, and the tricuspid once. Thirteen patients had valve lesions and in two there was a secondary superimposed bacterial infection. The primary lesion in all was of the type described by Gross

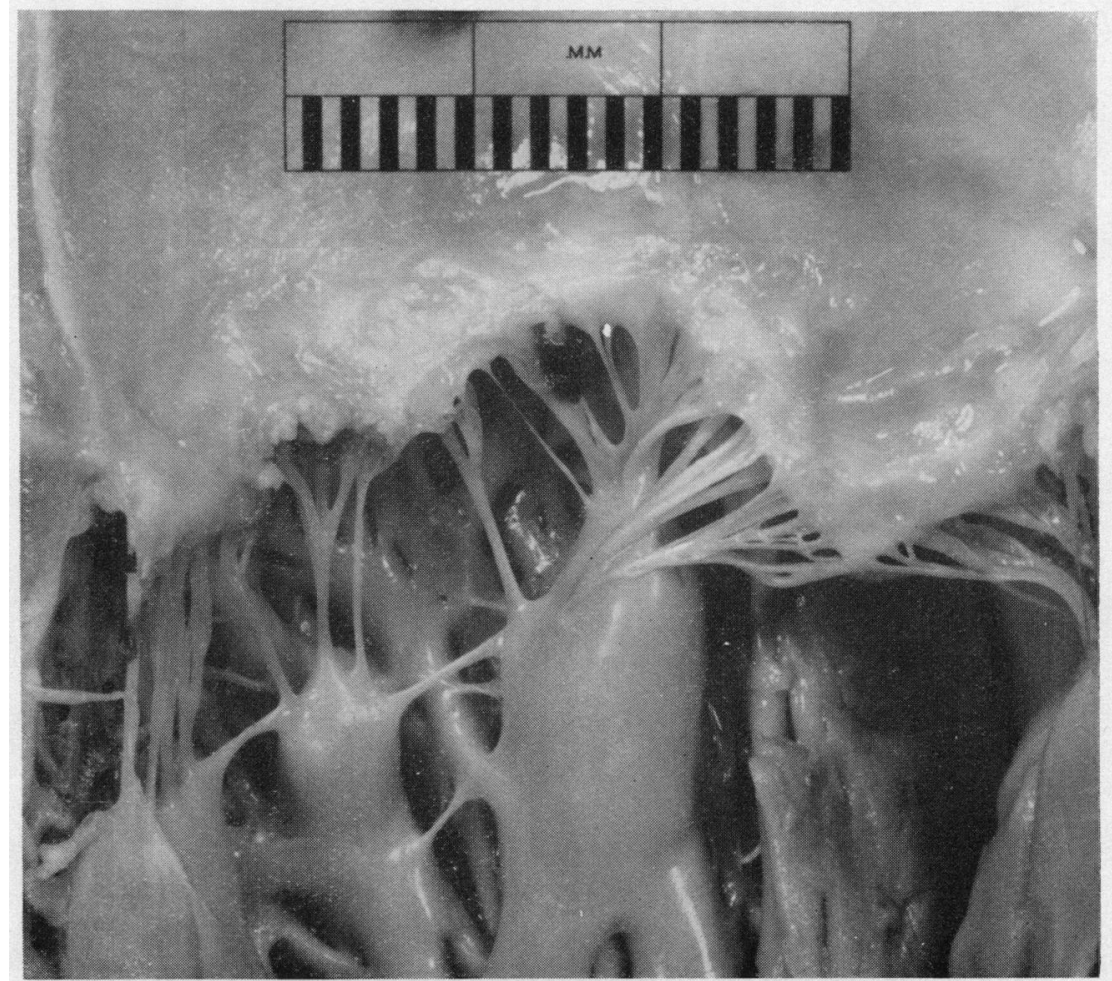

FIG. 1.-Mitral valve showing verrucous endocarditis with slight scarring in cusps but no lesion of the chordæ tendineæ. 


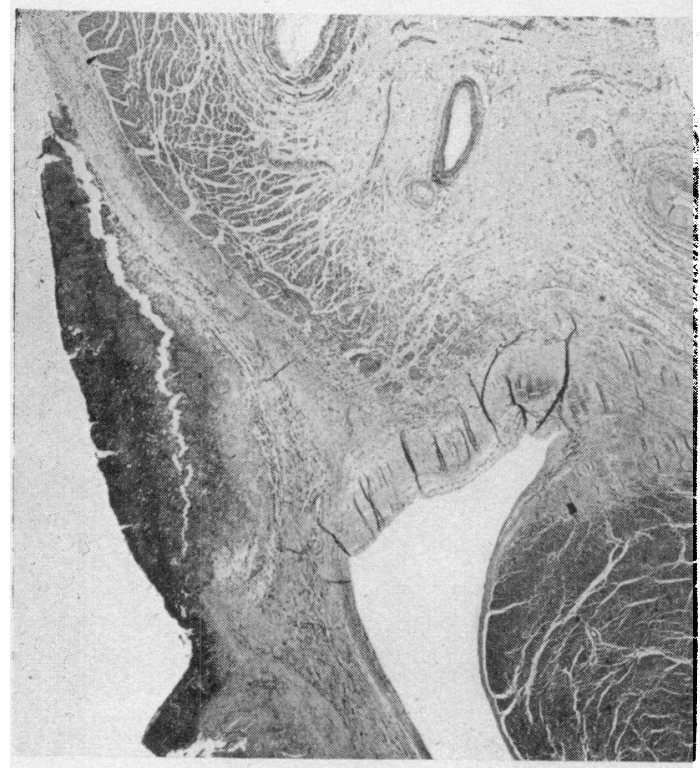

FIG. 2.-H. \& E. $\times 13$. Showing mitral valve with thickening and infiltration of endocardium in pocket and along auricular surface together with recent but organizing thrombus on valve. Note also intimal obliteration of vessels.

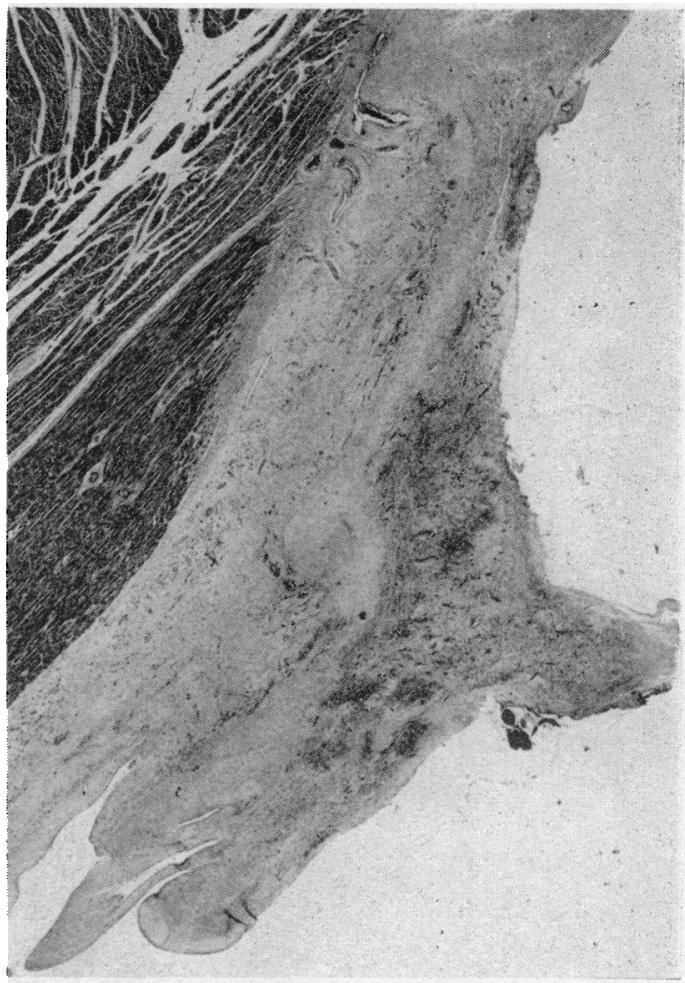

Fig. 3.-H. \& E. $\times 12$. Mitral valve showing gross chronic thickening and deformity with much tibrinoid and hæmatoxylin-staining degeneration, and some superficial fibrin.

(1932) and Klemperer et al. (1941), with multiplication of endothelial cells, proliferation of Anitschow myocytes, and infiltration of inflammatory mononuclear cells in the valve ring and in the base of the valve, particularly in the valve pocket (Fig. 4). Here, aggregations of hæmosiderin were frequently found and some fibrosis, indicating past inflammatory activity. In these areas, cells were seen undergoing karyolysis to form hæmatoxylin bodies, and this seemed to merge into eosinophilic fibrinoid material (Fig. 5). The mural endocardium, particularly in the neighbourhood of the mitral valve, showed proliferation of fibroblasts and myocytes (Fig. 6) often to form a dense granulomatous layer, sometimes arranged in almost a palisade fashion.

The Myocardium. Myocardial fibres themselves were seldom involved but in one case there was a patchy degeneration of some fibres, the nuclei thereof losing definition and resembling the inclusion body of an L.E. cell (Fig. 7). As far as we know this has not previously been described. Myocardial fibrosis was present in two cases and was associated with vascular occlusions (see below). In papillary muscles, interstitial nuclear proliferation and degeneration with pyknosis was seen (Fig. 8). In other cases abnormalities of the myocardium were chiefly interstitial and sometimes extensive (Fig. 9).

Frequently there was a fibrinoid lattice with cellular infiltration, and many of these cells were undergoing degeneration to hæmatoxylin bodies (Fig. 10); sometimes the lattice was acellular (Fig. 11). In some instances it appeared as if the fibrinoid lattice had formed on collagenous strands proceeding from an œdematous area of connective tissue (Fig. 12), perhaps as a result of motion and a mechanism similar to clot retraction. Thus it seems likely to us that the fibrinoid change so characteristic of this disease (and historically responsible for the popular but misleading 
term "collagen disease") derives mainly from clotting of fibrinogen occurring in areas of gelatinous exudate, but that occasionally local cellular infiltration occurs and the products of nuclear degeneration then contribute to "fibrinoid" in certain areas. Fibrinoid substances may in fact differ not only from disease to disease but also from site to site within a single organ.

The small vessels may show fibrosis affecting intima, media and adventitia (Fig. 13), and rarely acute necrosis. In two hearts extensive fibrosis had occurred in the myocardium due to widespread

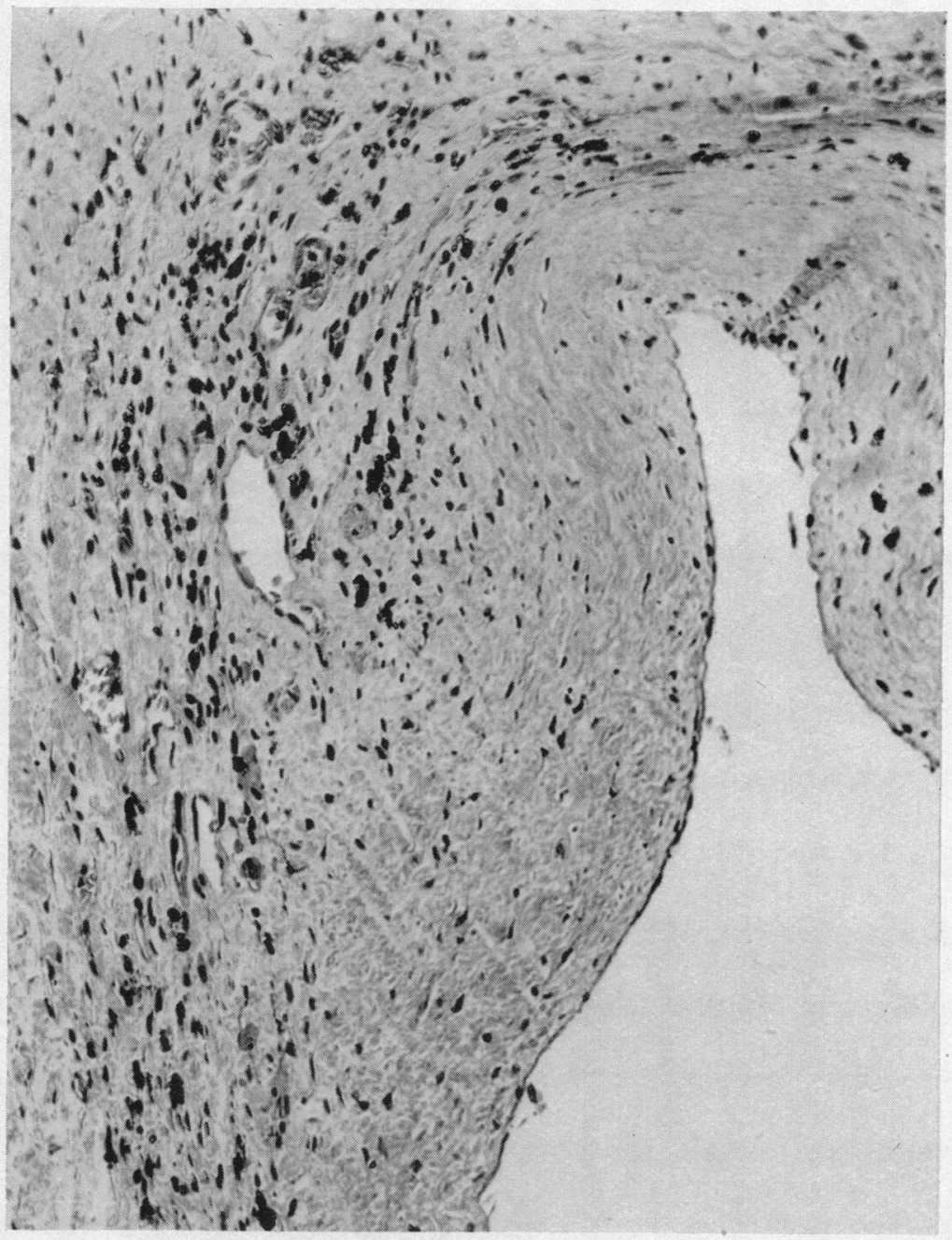

Fig. 4. - H. \& E. $\times 210$. Healed pocket lesion of the mitral valve.

arterial occlusion. This was longstanding in one case with recanalization (Fig. 14) and more recent in the other (Fig. 15), where thrombus was still adherent to the intima and covered by endothelium. More acute arterial lesions consisting of endothelial cell proliferation were also seen in the former case.

The pericardium was usually abnormal (20 out of 27 cases); mostly the layers were obliterated, occasionally there were deposits of fresh fibrin ( 2 cases), or an effusion (2 cases). Microscopical examination showed much fibrinoid change and many hæmatoxylin bodies. 


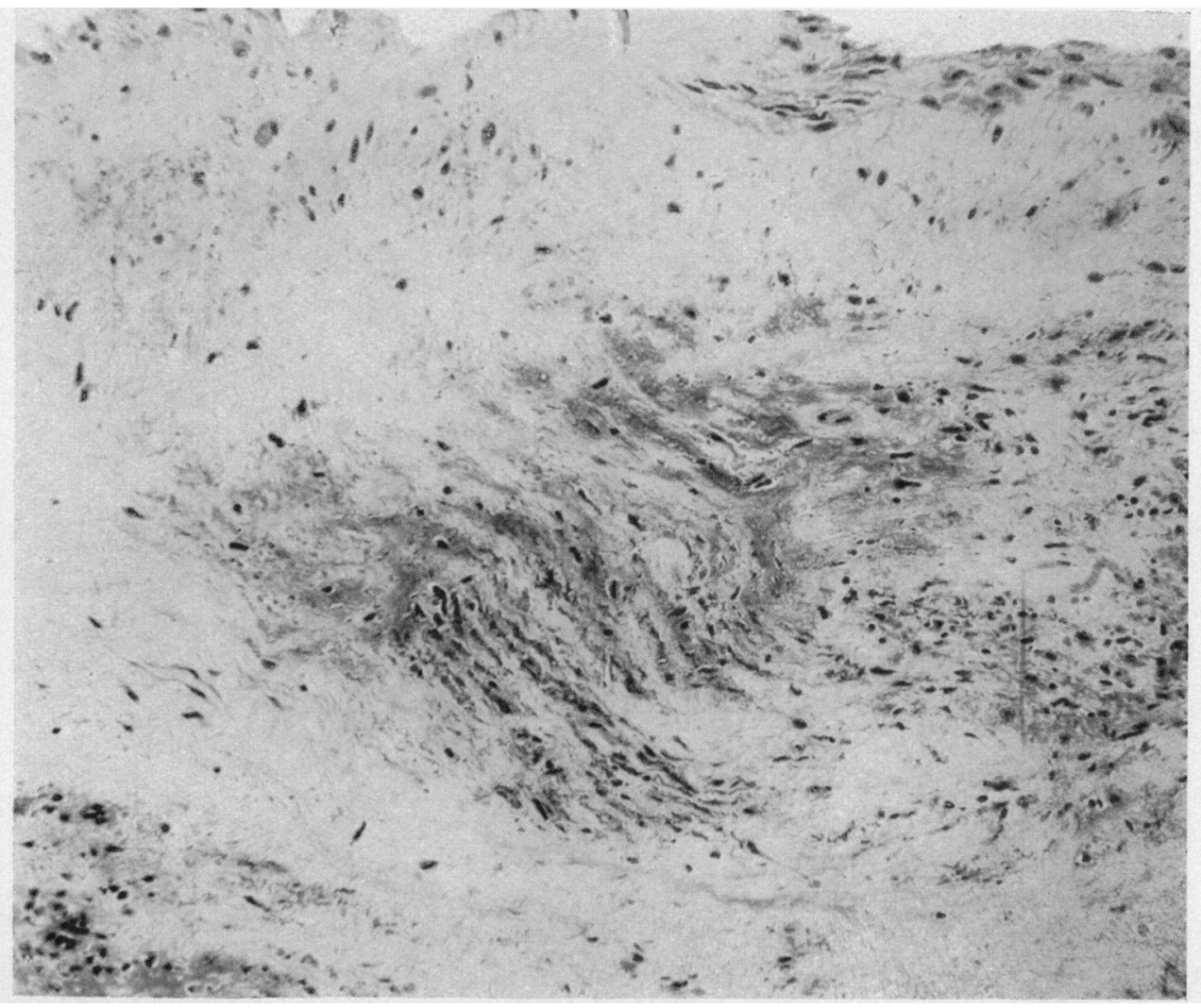

Fig. 5.-H. \& E. $\times 170 . \quad$ Mitral valve showing nuclei undergoing degeneration to form hæmatoxylin bodies and then fibrinoid.

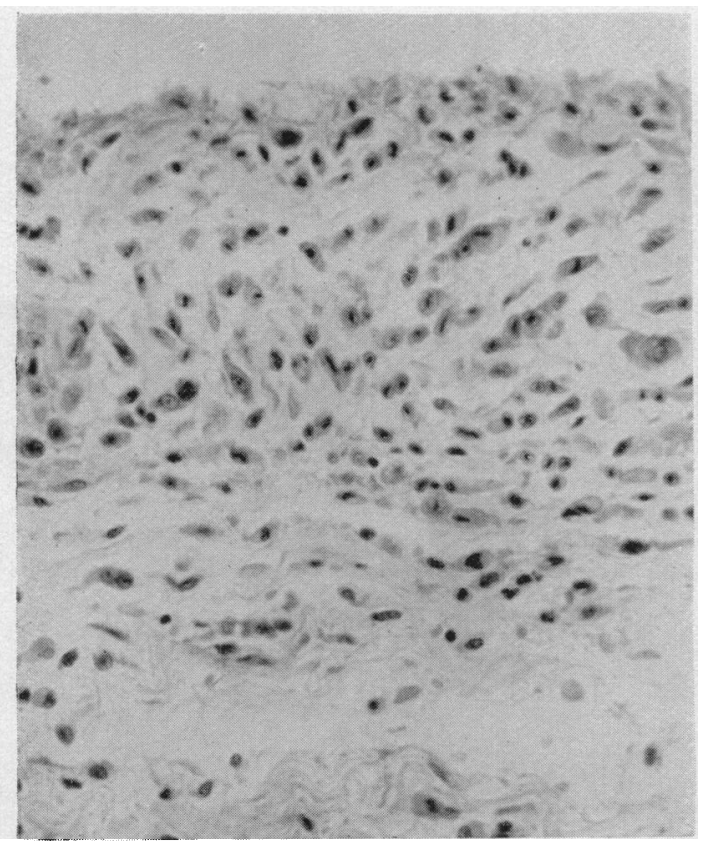

FIG. 6.-H. \& E. $\times 235$. Mural endocardium showing proliferation of fibroblasts and myocytes.

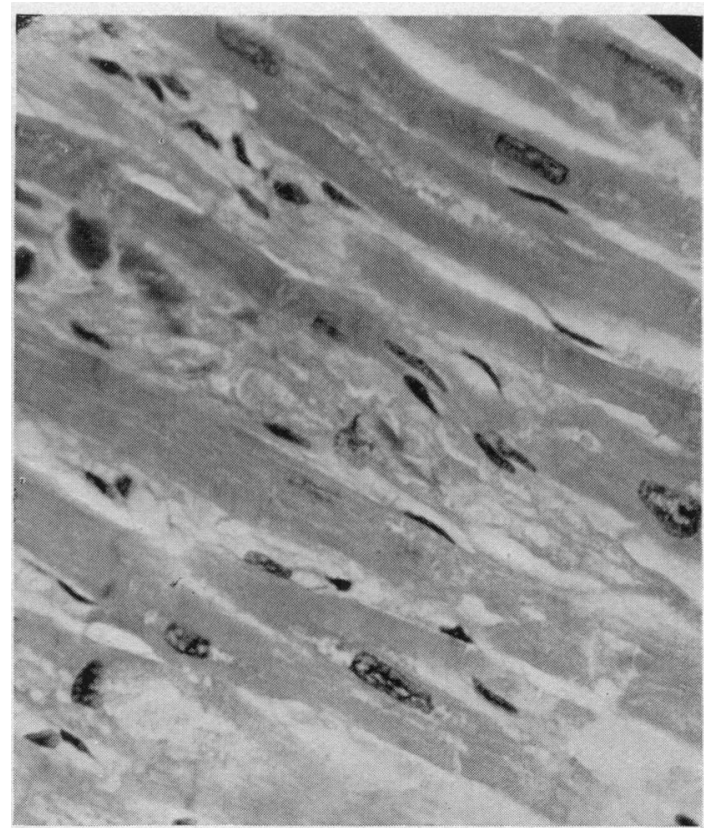

Fig. 7.-H. \& E. $\times 350$. Ventricular muscle fibres showing diffuse degeneration of certain fibres with nuclear transformation. 


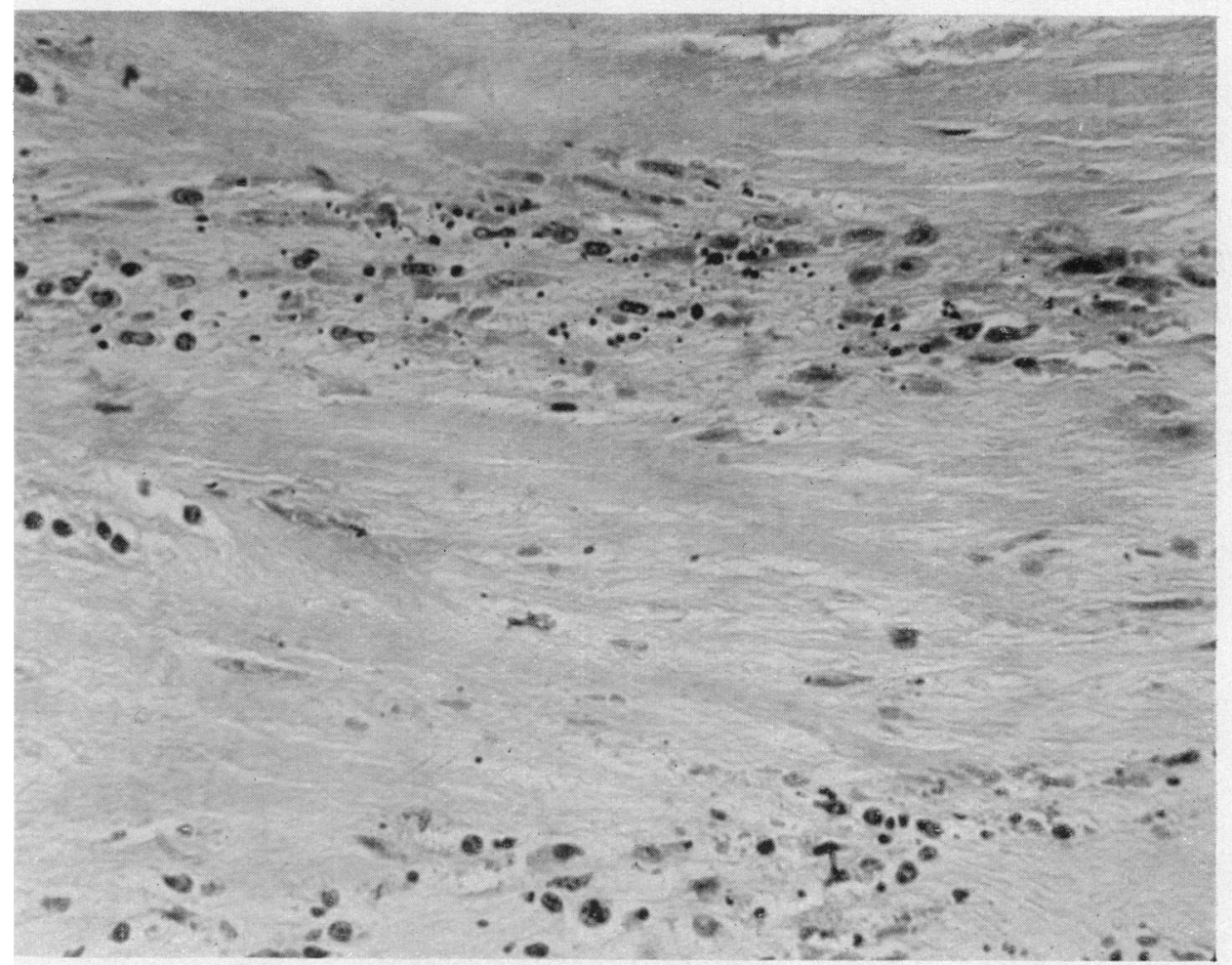

FIG. 8. - H. \& E. $\times 350$. Papillary muscle showing nuclear proliferation and degeneration to pyknotic debris.

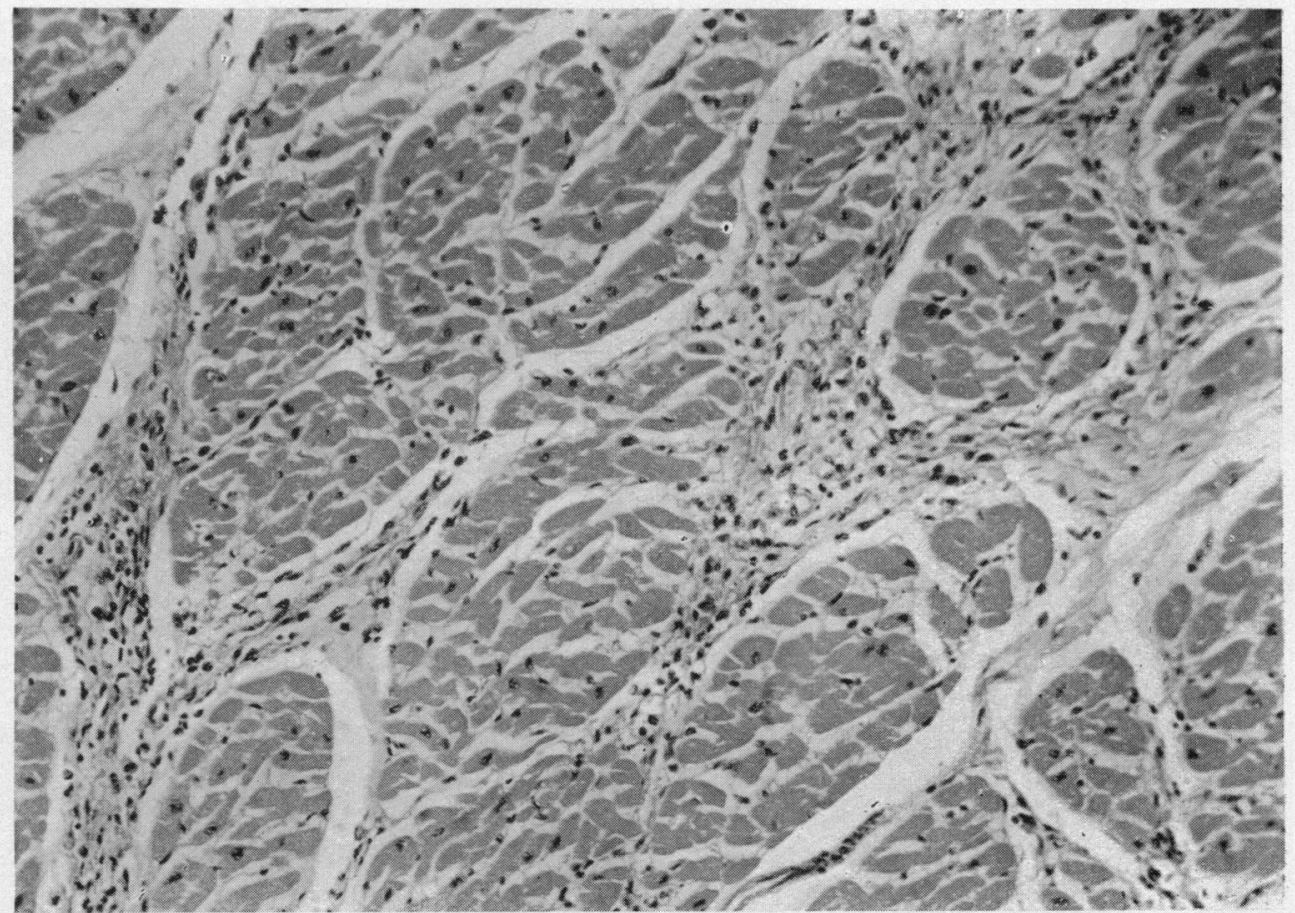

FIG. 9.-H. \& E. $\times 150$. Organized interstitial cellular infiltrate in myocardium. 


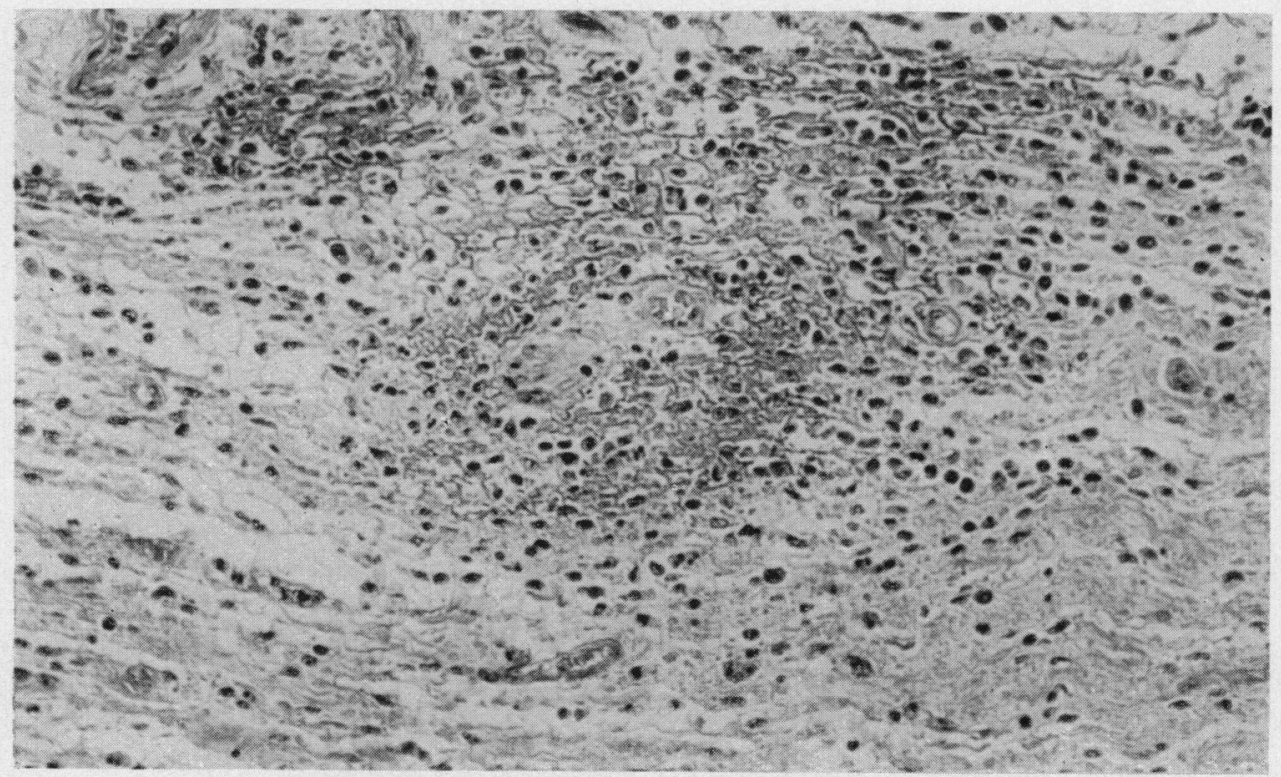

Fig. 10. - H. \& E. $\times 210$. Fibrinoid lattice with cellular infiltration.

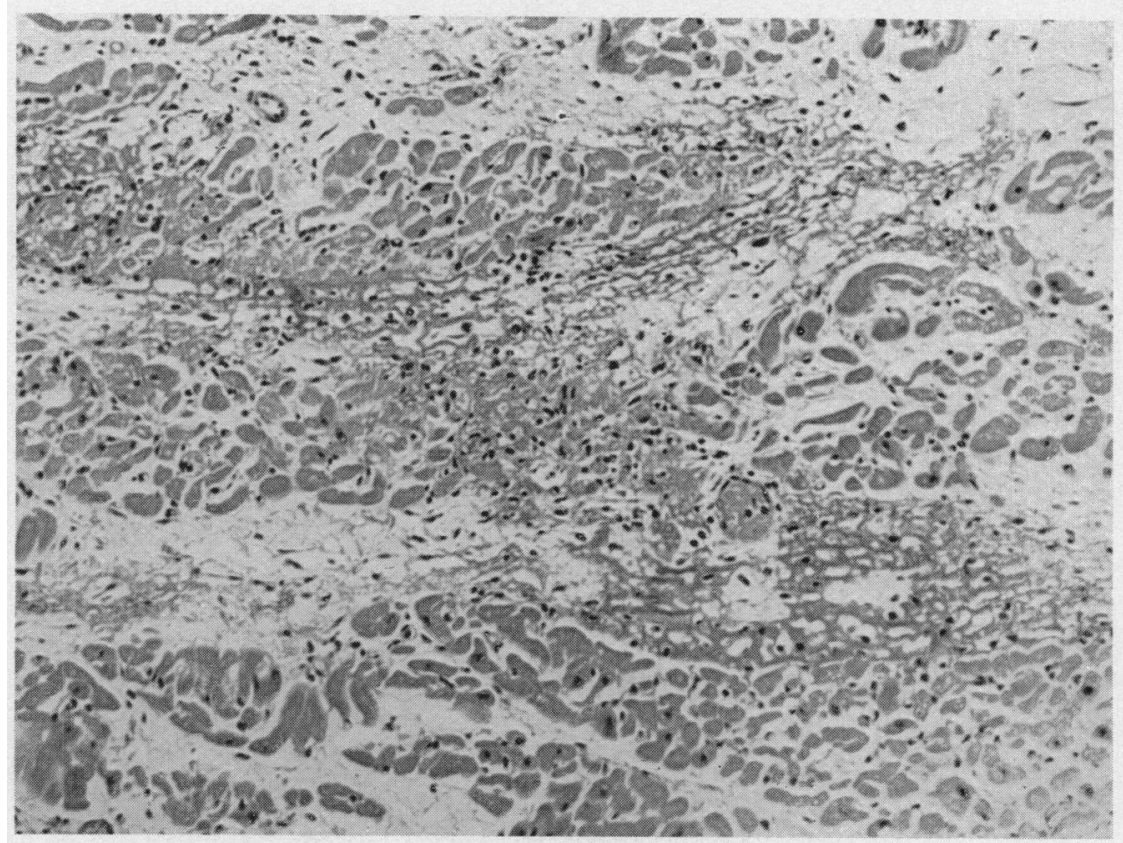

FIG. 11.-H. \& E. $\times 105$. Relatively acellular fibrinoid lattice between œdematous muscle bundles.

The Clinical Features of Lupus Carditis:

The incidence of cardiac manifestations in the 60 cases is shown in Table II.

Endocarditis. The diagnosis of valvular endocarditis of any type is based on the recognition of organic murmurs. In lupus we have found that these murmurs are sometimes soft and transient (Fig. 16) so that diagnosis is often difficult and easily overlooked. The commonest finding is of a 


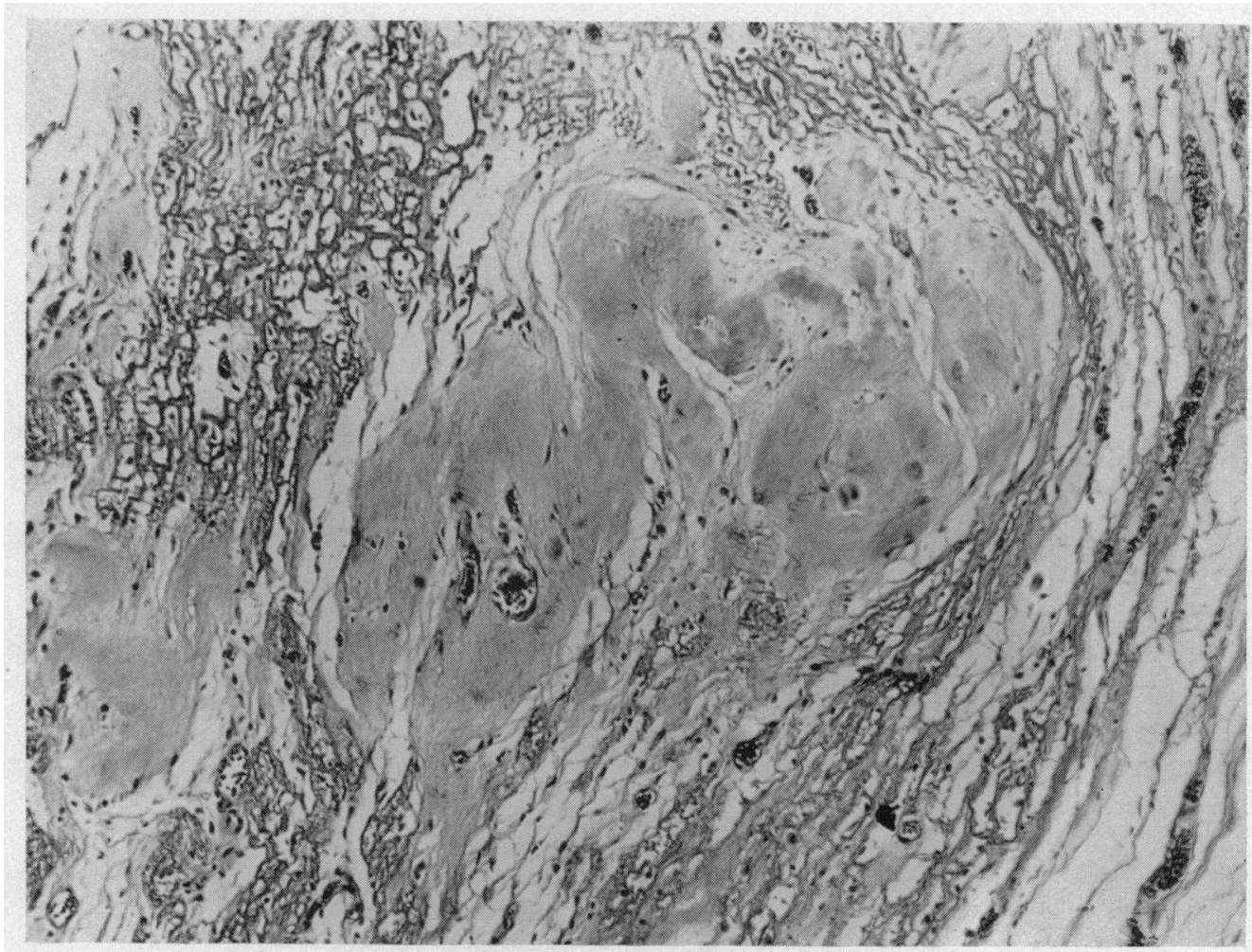

FIG. 12.-H. \& E. $\times 80$. Fibrinoid lattice in myocardium showing transition from gelatinous œdema.

mid-systolic murmur which is indistinguishable from an innocent murmur and therefore difficult to assess. We have accepted all pan-systolic murmurs and all diastolic murmurs as evidence of endocarditis.

Griffith and Vural (1951) found endocardial lesions at necropsy in 8 out of 18 cases, of which only one had been known to have a mitral diastolic murmur and two others had systolic murmurs of doubtful significance. Shearn and Pirofsky (1952) diagnosed mitral valve disease on the finding of an apical diastolic murmur in four patients and Libman-Sacks endocarditis of the mitral valve was found in two that came to necropsy. Harvey et al. (1954) found that apical systolic murmurs were frequent in cases with carditis and in those without; they correctly diagnosed mitral valve disease on the basis of an apical diastolic murmur in two cases but considered that the presence of endocarditis usually had little or no effect on the heart or circulation.

It is clear that there is difficulty in recognition of lupus endocarditis and in our own experience although 13 of the 27 necropsy cases showed endocarditis we recognized definite organic murmurs in only 12 of the 60 patients. Twenty-eight others had a midsystolic murmur heard best at the left sternal edge or base and considered to be functional or incidental to tachycardia, fever, anæmia or a raised blood pressure. None of these murmurs was associated with evidence of valve obstruction or loud enough to make it certain that the murmur indicated organic disease.

Mitral valvulitis was recognized in seven patients of whom two had pan-systolic murmurs oniy, two had a mitral diastolic murmur only, and the remainder had both. Two had evidence of aortic regurgitation as well as mitral valve disease.

One patient with an isolated pan-systolic murmur died, and necropsy showed verrucous vegetations on the mitral valve: another, who had given a history of rheumatism in childhood and had mitral systolic and diastolic murmurs and an aortic diastolic murmur, showed verrucous vegetation on the aortic valve and slight fusion of the mitral cusps. 


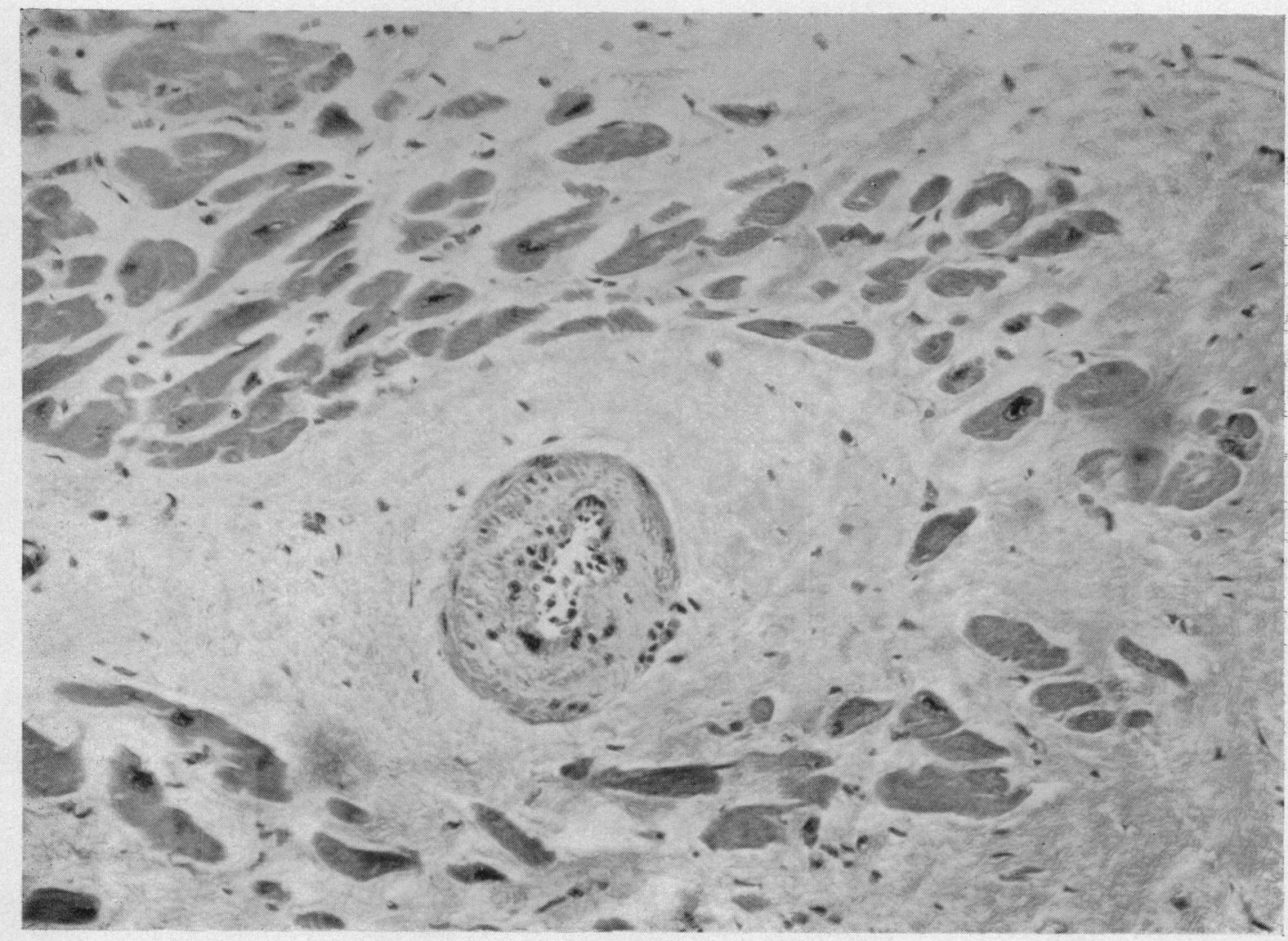

Fig. 13. - H. \& E. $\times 200$. Myocardial vessel showing recanalization and scarring of vessel with myocardial fibrosis .

Another patient was of great interest as she developed signs of mitral stenosis while under observation, and necropsy showed mild mitral stenosis with recent vegetations. The illness started with persistent "chilblains" and erythema after pneumonia. L.E. cells were found in the peripheral blood. Two years later mild polyarthritis and a further attack of lung infection developed: until this the heart had been clinically normal, including the electrocardiogram and phonocardiogram. During the following year a mitral systolic murmur, presystolic murmur, and opening snap developed (Fig. 17). There was persistent fever and raised sedimentation rate despite cortisone. Pericarditis and atrial fibrillation developed. Finger pulp lesions, psychosis, and persistent albuminuria occurred during the period: deterioration and death were due to a pyocyaneus pneumonia four years after the onset of symptoms. This was the only case showing clinical evidence of stenosis rather than non-obstructive valvulitis.

In addition to four patients with a pansystolic murmur there was another woman of 34 in whom a late apical systolic murmur indicated valve disease. At necropsy there were scattered vegetations on the inferior surface of the mitral valve.

The mitral valve is the commonest site of inflammation in lupus erythematosus as in rheumatism. Cusp fusion may develop but is rarely sufficient to produce symptoms and signs of obstruction or serious regurgitation. Bacterial endocarditis developed on the mitral valve in one patient. Necropsy showed a pulmonary valvulitis in one, and a tricuspid valvulitis in another such as had been described by Gibson and Wood (1955). The patient with tricuspid valvulitis and four others in the necropsy series had unsuspected mitral valve disease and in two of these there was fusion of the mitral cusps at their edges in association with active lupus endocarditis.

Aortic valvulitis was recognized by finding an aortic diastolic murmur in six patients of the 


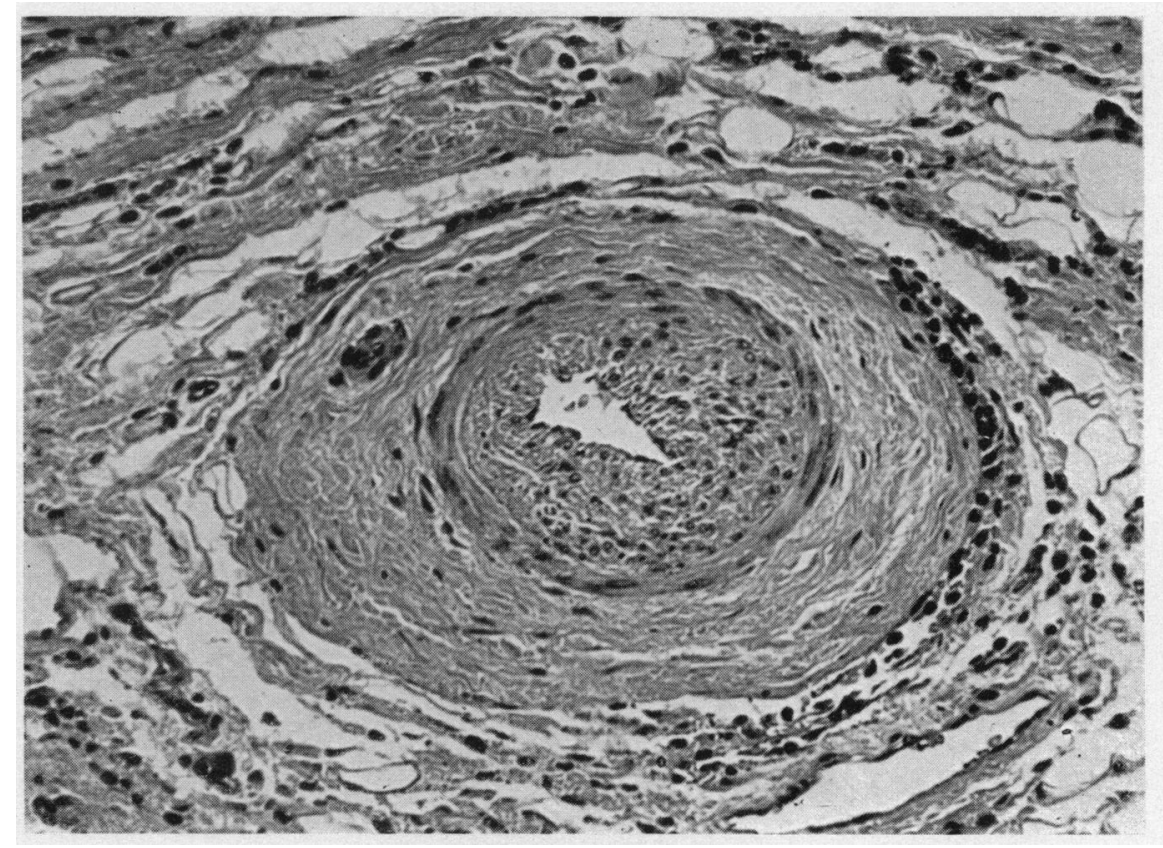

FIG. 14.-H. \& E. $\times 200$. Scarred artery with subintimal fibromuscular cell proliferation and "onion-peel" fibrosis of adventitia.

whole series ( 2 of these had signs of mitral valve disease also). Two came to necropsy: valvulitis was confirmed in one and unconfirmed in another who had slight aortic regurgitation associated with severe systemic hypertension. In the necropsy series four patients had organic aortic valve disease but in only one of these was it recognized in life.

Myocarditis. The clinical detection of myocarditis in disseminated lupus erythematosus is difficult because the development of heart failure is often associated with such factors as hypertension, pericarditis, and sodium and water retention due to renal disease or steroids. Furthermore, increase in the heart shadow on X-ray may be due to the development of an effusion or of hypertension. The observed development of a softening of the first heart sound, the appearance of a third heart sound, or the occurrence of frequent extrasystoles in the known absence of the factors mentioned above would indicate myocarditis but in our experience this is rare. Only two patients in the series developed an arrhythmia-atrial flutter with a 2:1 block developed terminally in one case, and atrial fibrillation developed in another. There were no cases where heart failure could be attributed solely to myocarditis.

In a few cases there was histological evidence of myocardial disease with fibrinoid change and fibrosis. This muscle damage never appeared to be severe, although it may contribute to the early development of cardiac failure when there is also systemic hypertension.

In the electrocardiogram slight abnormalities affecting the $\mathrm{S}-\mathrm{T}$ segment and $\mathrm{T}$ wave were mostly associated with evidence of pericarditis and were usually interpreted as such. Prolongation of conduction time of either P-R, QRS, or Q-T interval in the absence of a caus z for ventricular hypertrophy is good evidence of cardiomyopathy but these signs were not encountered.

Pericarditis. It is well known that pericarditis occurs during the course of systemic lupus but it is not widely recognized that pericarditis occurs in almost all cases at some stage of the disease. Pericarditis was not found in 7 of the 27 necropsy cases but five of these had died exceptionally early in the course of the disease, the duration of symptoms being only $4,5,9,10$, and 19 months. The cause of death was an acute intercurrent infection in four and rapidly increasing 


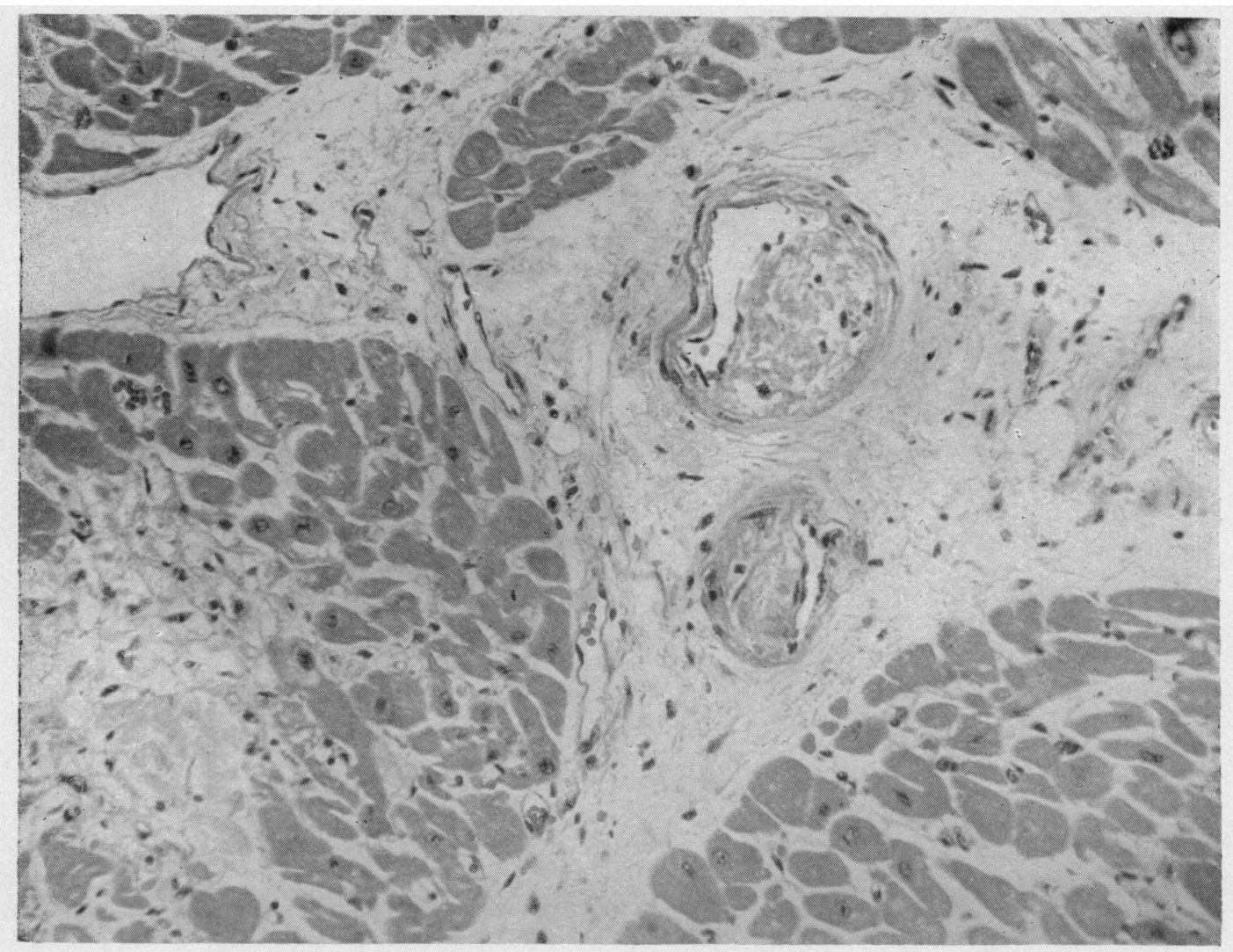

FIG. 15.-H. \& E. $\times 200$. Myocardial fibrosis with thrombotic vascular obliteration.

renal failure in the fifth: in one case pericarditis was recognized by a pericardial rub and marked S-T elevation in the cardiogram, but these findings were transient and no pericardial abnormality was found at necropsy. Pericarditis may be a continuing process but more often it appears as an isolated attack or as recurrent brief episodes; such attacks may be unaccompanied by symptoms.

The typical anterior chest pain of pericarditis occurred in 17 of 60 cases and 13 of them had pericardial friction at the same time. More patients had friction than pain (26 out of 60). Friction is sometimes present for only a few hours and is readily missed for this reason. Many patients showed an increase of fever and heart rate accompanying an attack of pericarditis; a careful scrutiny of accurate temperature and pulse charts is necessary to detect these changes, which are not always obvious because of pre-existing fever from the general disaase.

Dyspnœa is a common symptom in disseminated lupus erythematosus because of pulmonary disease; it usually increases at the time of an attack of pericarditis. Severe tamponade is rarely seen and a significant rise in jugular venous pressure that could be directly attributable to the development of a pericardial effusion occurred in only 5 of the 60 . We have found that interpretation of a rise in jugular venous pressure is particularly difficult during active phases of this condition, as the explanation may lie in water retention associated with steroid therapy or in myocardial failure, either or both of which may be present as well as a pericardial effusion. Serial $\mathrm{X}$-rays show that pericardial effusions may be of slight to moderate size and frequently resorb rapidly (20 out of 60 showed radiological evidence of effusion with resorption).

Almost all patients (52 out of 60) showed at some stage of the disease electrocardiographic abnormalities that were consistent with acute or chronic pericarditis (Fig. 18) or with pericardial effusion 
(Fig. 19). Slight T-wave changes or transient elevation of S-T segments were characteristic. After severe attacks the $\mathrm{T}$ waves rarely recovered their original voltage. Effusions were sometimes accompanied by a great drop in voltage of the QRS-T in all leads. After the effusion resorbed (Fig. 19) normal voltage was restored. Although two patients with abnormal T waves were found at necropsy to have myocardial infarcts, it was impossible in the absence of pathological $Q$ waves to distinguish their electrocardiograms from those of cases with pericarditis alone.

At necropsy 20 out of the 27 cases showed evidence of recent or old pericarditis. In those showing recent effusion the duration of the disease had been one to three years, whereas in others showing chronic adhesions the duration had been from two to eleven years, and in some of these the space was totally obliterated. None of these patients had evidence of constrictive pericarditis. Four of the 7 cases in which the pericardium was normal had died within one year of the onset of the disease.

Hypertension. Humphreys (1948) suggested that in the absence of renal disease the blood pressure in systemic lupus erythematosus is normal or more often low. Griffith and Vural (1951) recorded that 7 of their 18 patients had renal involvement, and 4 of these were the only patients to develop hypertension: they stated that hypertension was infrequent during the early phases of systemic lupus and when present was associated with advanced renal abnormalities. The incidence 


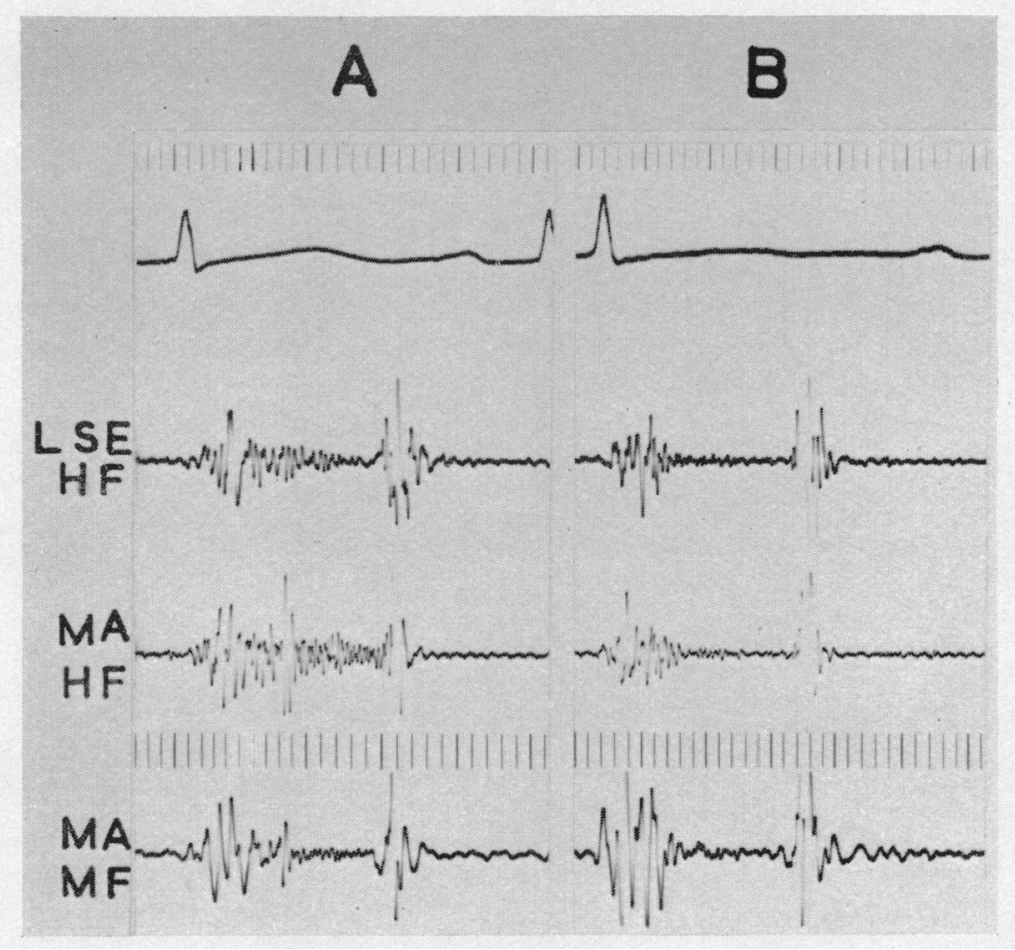

FIG. 16.-Phonocardiograms showing a pan-systolic murmur and systolic click at the mitral area (A) which disappeared a month later (B). $\mathrm{HF}=$ high frequency. $\mathrm{MF}=$ medium frequency. $\mathrm{MA}=$ mitral area. $\mathrm{LSE}=$ left sternal edge.

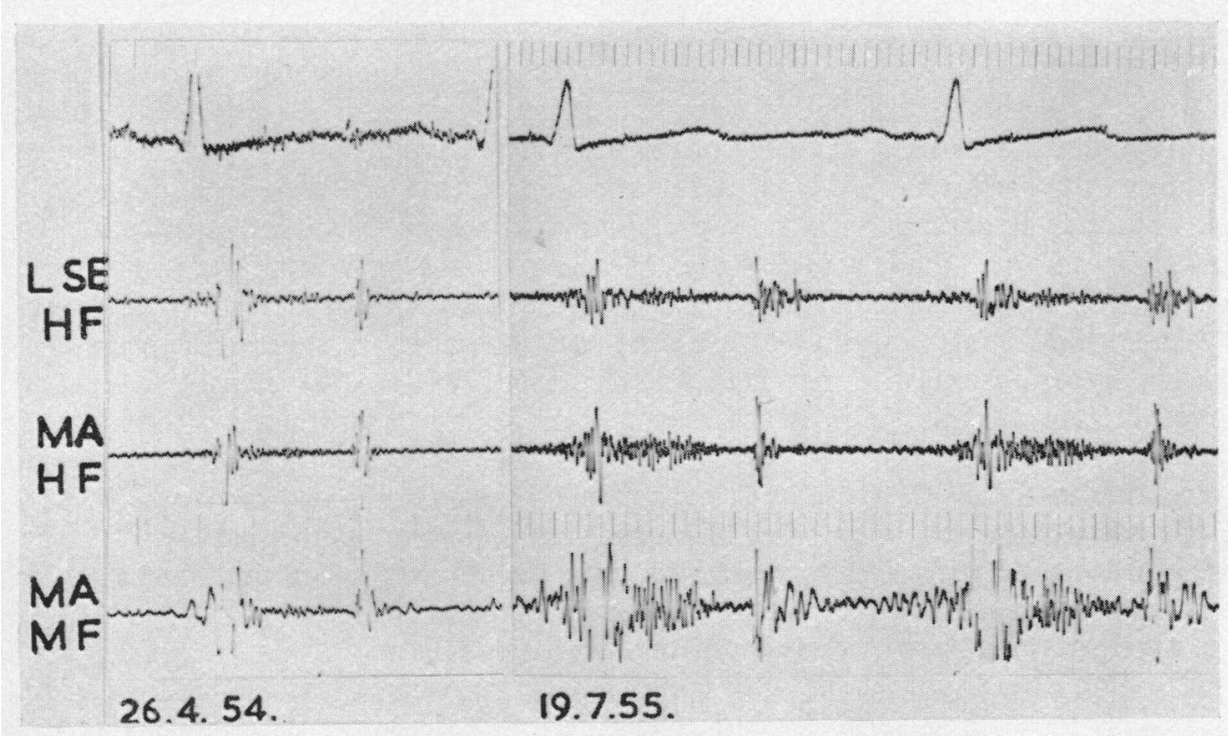

FIG. 17.-Phonocardiograms showing the development of systolic and diastolic murmurs due to lupus endocarditis of the mitral valve. 
of cases with hypertension had been estimated at 14 per cent by Harvey et al (1954) and at 32 per cent by Shearn and Pirofsky (1952). The corresponding figure in the present series was 44 per cent.

Twenty-six of our 60 patients developed a diastolic blood pressure of over $95 \mathrm{~mm}$. of mercury. This hypertension was attributed to renal disease in 20 of these; 19 had proteinuria of at least $100 \mathrm{mg} . / 100 \mathrm{ml}$. and one other had a blood urea of $100 \mathrm{mg} . / 100 \mathrm{ml}$. Steroid therapy had been given in 13 of these and this occasionally aggravated the hypertension. Of the six patients who developed hypertension without evidence of renal disease. steroid therapy had been given in four: the remaining two were both considered to have incidental essential hypertension.

In eight patients hypertension was severe, with a diastolic blood pressure of $130 \mathrm{~mm} . \mathrm{Hg}$. or more. Four of these had papillœdema. One presented with hypertensive encephalopathy before any treatment for systemic lupus was given. Three others developed a rising diastolic pressure and papillœdema - two of them while on cortisone at a late stage of their disease. In one patient severe hypertension with papillœdema responded well to hypotensive drugs, with great improvement in general condition and eye signs. Cortisone was continued throughout the period of hypotensive drug therapy.

We were able to follow 21 patients for a sufficiently long period to compare the severity and duration of hypertension with the degree of myocardial hypertrophy at necropsy. The correlation was good in 18 but the other 3 appeared to have developed myocardial hypertrophy without hypertension: one of these was the patient with bacterial endocarditis.

Pulmonary hypertension was considered to have been present in two patients. One of these had extensive lung disease associated with clinical evidence of right ventricular hypertrophy which was confirmed electrocardiographically and at necropsy. In the other right ventricular hypertrophy was a necropsy finding.

Heart Failure. Congestive cardiac failure developed in 22 cases. Systemic hypertension was 


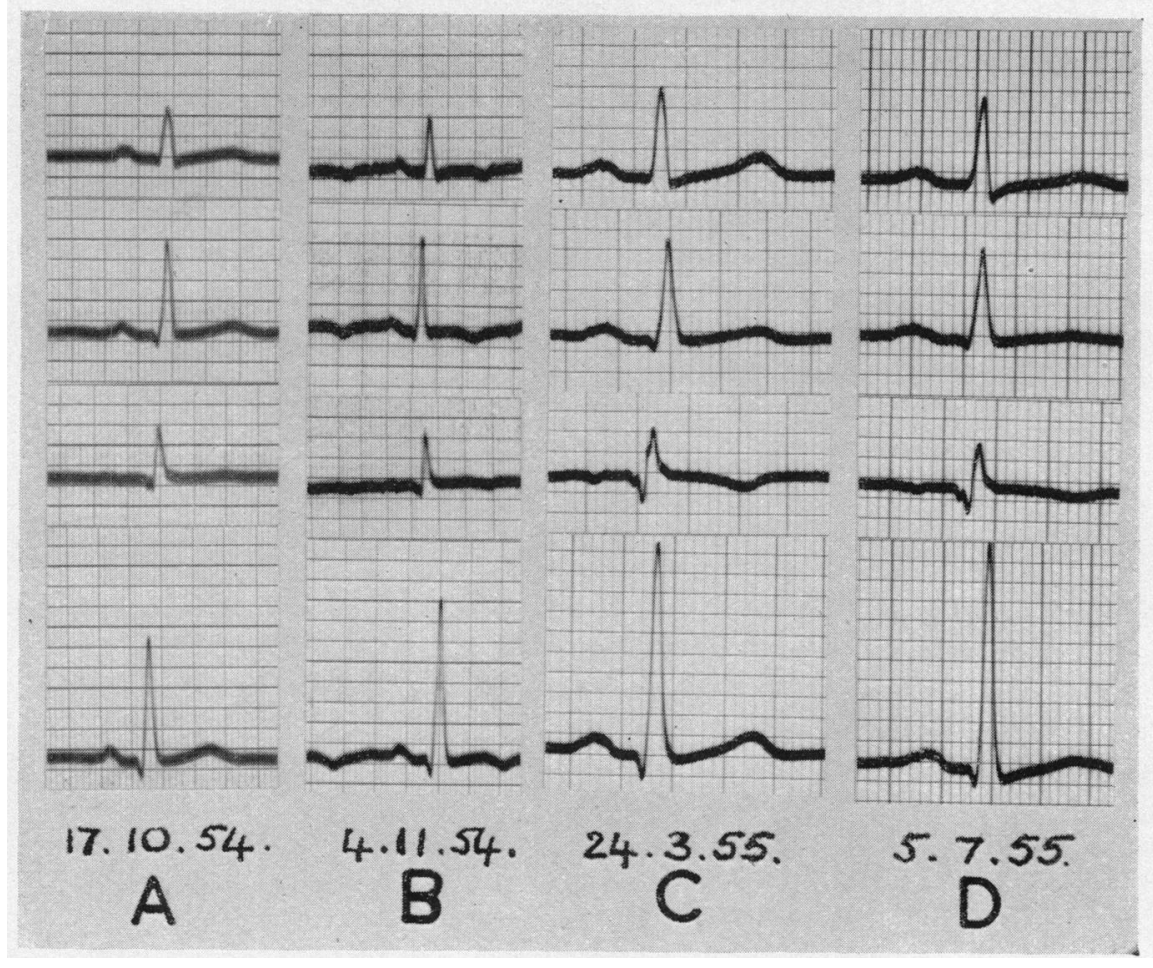

FIG. 19.-Electrocardiograms (leads I, II, III, and V6) showing changes due to pericarditis with pericardial effusion ( $A$ and $B$ ) and subsequent resolution with persistent $T$ wave changes (C and $\mathrm{D})$.

the main cause but it was rarely the sole factor responsible for failure: pericarditis was often present, and in nearly all cases there were other factors predisposing to failure such as fever, secondary infection, anæmia, and sodium and water retention due to steriod therapy. The onset was usually gradual and acute left ventricular failure was seldom seen. Five cases developed heart failure with a low or normal blood pressure; three of these had pericarditis and one had bacterial endocarditis. There were no cases in which myocarditis was considered the sole cause of failure. The response of heart failure to sodium restriction, digitalis, and mersalyl was usually poor.

Heart failure is generally made worse by salt-retaining hormones but in two patients an increase in the dose of cortisone controlled the disease better and heart failure improved.

\section{SumMARY AND CONCLUSIONS}

Carditis occurs in the majority of cases of systemic lupus erythematosus. The commonest manifestation is pericarditis. This is rarely absent except in those where the history is short. It is often painless and is frequently accompanied by an effusion; it may be recurrent and often becomes chronic and adhesive, though constrictive pericarditis is not seen. Histologically, there are fibrinoid changes and hæmatoxylin bodies: intimal fibrosis or acute necrotizing lesions may be present in the small vessels.

Endocarditis is present in about half of the necropsy cases. It rarely results in significant valvular obstruction or regurgitation, and for this reason is not recognized in life as frequently as it is found at necropsy. The diagnosis is made by the finding of an organic murmur. Valves of the left side of the heart are affected far more commonly than those of the right side, and bacterial endocarditis may supervene. Lesions commonly occur in the base of the valve, particularly in the valve pocket 
and histologically there are numerous endothelial cells, Anitschow myocytes, and inflammatory mononuclear cells; disintegration of these cells results in the formation of hæmatoxylin bodies and eosinophilic fibrinoid material.

Myocarditis is not common on histological examination. It is extremely difficult to recognize during life because of its association with pericarditis, hypertension, and possible water retention. Myocardial damage is chiefly interstitial, though the nuclei of myocardial fibres have been seen to undergo degeneration, and there may also be myocardial fibrosis as a result of arterial occlusion. Degeneration of the nuclei of infiltrating cells produces hæmatoxylin bodies and may contribute to fibrinoid material; but another, and possibly more important, source of fibrinoid material is inflammatory exudate containing fibrinogen and other plasma proteins.

Hypertension is commonly related to renal disease or hormone therapy and may reach malignant levels. Sometimes it can be controlled by ganglionic-blocking agents. Hypertension is an important cause of heart failure, which is usually due to a variable combination of factors such as pericarditis, endocarditis, myocarditis, and sodium and water retention due to renal disease or steroid therapy.

The electrocardiogram is probably abnormal at some stage of the disease in all cases though the abnormalities may be transient. Commonest signs are in the $\mathrm{T}$ wave and $\mathrm{S}-\mathrm{T}$ segment due to pericarditis; there may be evidence of left ventricular hypertrophy due to systemic hypertension, or rarely, right ventricular hypertrophy due to pulmonary hypertension. There are no changes that certainly indicate the presence of myocarditis as distinct from those produced by pericarditis, hypertrophy, and electrolyte change.

The commonest cause of enlargement of the cardiac shadow on X-ray is pericardial effusion which is usually transient. Progressive enlargement is usually due to heart failure from a combination of the factors mentioned above.

Thanks are due to our colleagues in each hospital who kindly allowed us to see their patients and use their data, and in particular to Prof. Dorothy Russell, Dr. L. E. Glynn, Dr. I. Doniach, Prof. R. V. Harrison, and Prof. J. H. Dible for use of pathological data and material. We are also indebted to Mr. P. J. Fiske for the illustrations.

\section{REFERENCES}

Baehr, G., Klemperer, P., and Schifrin, A. (1935). Tran. Ass. Amer. Physicians, 50, 139. Griffith, G. C., and Vural, I. L. (1951). Circulation, 3, 492.

Gross, L. (1932). Libman Anniversary Volume, 2, 527, New York, The International Press.

Harvey, A. M., Shulman, L. E., Tumulty, P. A., Conley, C. L., and Schoenrich, E. H. (1954). Medicine, 33, 291.

Humphreys, E. M. (1948). Ann. intern. Med., 28, 12.

Kaposi, M. K. (1872). Arch. Dermat. Syph., 4, 36.

Klemperer, P., Pollack, A. D., and Baehr, G. (1941). Arch. Path., 32, 569.

Libman, E., and Sacks, B. (1924). Arch. intern. Med., 33, 701.

Shearn, M. A., and Pirofsky, B. (1952). Arch. intern. Med., 90, 790.

Wood, P., and Gibson, R. V. (1955). Brit. Heart J., 17, 552. 